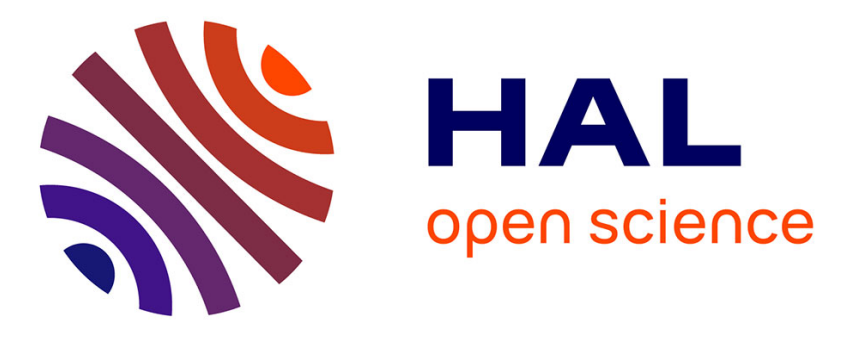

\title{
Impact of cyclic compressive loading and moisture content on the mechanical behavior of Aucoumea Klaineana Pierre
}

Claude Feldman Pambou Nziengui, Samuel Ikogou, Rostand Moutou Pitti

\section{- To cite this version:}

Claude Feldman Pambou Nziengui, Samuel Ikogou, Rostand Moutou Pitti. Impact of cyclic compressive loading and moisture content on the mechanical behavior of Aucoumea Klaineana Pierre. Wood Material Science and Engineering, 2017, 13 (4), pp.190 - 196. 10.1080/17480272.2017.1307281 . hal01909282

\section{HAL Id: hal-01909282 \\ https://hal.science/hal-01909282}

Submitted on 1 Nov 2018

HAL is a multi-disciplinary open access archive for the deposit and dissemination of scientific research documents, whether they are published or not. The documents may come from teaching and research institutions in France or abroad, or from public or private research centers.
L'archive ouverte pluridisciplinaire HAL, est destinée au dépôt et à la diffusion de documents scientifiques de niveau recherche, publiés ou non, émanant des établissements d'enseignement et de recherche français ou étrangers, des laboratoires publics ou privés. 


\title{
Impact of cyclic compressive loading and moisture content on the mechanical behavior of Aucoumea Klaineana Pierre
}

\author{
Claude Feldman PAMBOU NZIENGUI ${ }^{1,2}$, Samuel IKOGOU ${ }^{1}$, Rostand MOUTOU PITTI ${ }^{2,3}$ \\ ${ }^{1}$ Ecole Nationale des Eaux et Forêts, BP 3960, Libreville, Gabon \\ ${ }^{2}$ Université Clermont Auvergne, CNRS, Institut Pascal, BP 10448, 63000 Clermont-Ferrand, France \\ ${ }^{3}$ CENAREST, IRT, BP 14070, Libreville, Gabon
}

\begin{abstract}
The mechanical behavior of Aucoumea Klaineana Pierre (AKP) under progressive static and cyclic compressive loading at various moisture content (MC) stages is investigated herein. This tropical species, also called Okume, originates from the Congo Basin, particularly Gabon. The experimental device used is composed of: an electronic testing machine, a system yielding the corresponding $\mathrm{MC}$, and $A K P$ wood samples. In all, $15 A K P$ samples were loaded in statics, at different MC levels, until the first cracks led to characterizing the mechanical behavior of the species in static compression along the longitudinal direction. Next, 7 samples of $A K P$ were gradually loaded at distinct MC values, with 5 under cyclic longitudinal compression. Results show that under a static longitudinal compressive loading, the modulus of elasticity (MOE) of $A K P$ decreases as sample MC increases. For the cyclic compressive loading after the first cycle, sample MOE increases with both the intensity and number of loading cycles as well as with the permanent deformation of each cycle. Moreover, it can be observed that within the plasticity domain, the impact of MC variation on the mechanical behavior of $A K P$ is negligible.
\end{abstract}

Keywords: Tropical species, Congo Basin forest, Okume, experiment.

\section{Nomenclature}

$\begin{array}{ll}\text { AKP } & \text { Aucoumea Klaineana Pierre } \\ \delta & \text { Specimen density } \\ t & \text { Specimen thickness } \\ \mathrm{L} & \text { Specimen height } \\ M C & \text { Moisture Content } \\ w & \text { Specimen width } \\ P D & \text { Amplitude of permanent deformation } \\ F S P & \text { Fiber Saturation Point } \\ M O E & \text { Modulus of elasticity } \\ l_{i} & \text { Amplitude of cycle } i \\ M & \text { Specimen mass } \\ M_{H} & \text { Specimen mass at a specific MC } \\ M_{0} & \text { Specimen mass in the dry state }\end{array}$




\section{Introduction}

In central Africa and particularly in the equatorial region, the forest plays a key role in regulating our environment by sequestering greenhouse gases (Odounga et al. 2016). In the year 2000, Gabon produced over 4 million $\mathrm{m}^{3}$ of timber (Medzegue et al. 2007), of which 72\% was Aucoumea Klaineana Pierre $(A K P)$. This species is mainly used for plywood construction, in veneer, and finished or semi-finished products such as pulp and paper (Manfoumbi Boussoungou et al. 2010, 2012 , 2014). In addition, $A K P$ is essential to the construction of timber structures including bridges, especially in this country's most remote places (Ikogou et al. 2016). However, with over 1,900 mm of annual precipitation, around $85 \%$ relative humidity and a mean temperature near $27^{\circ} \mathrm{C}$, the environmental conditions in Gabon are very arduous. Consequently, the mechanical behavior of $A K P$ largely depends on temperature and moisture changes (Ndong Meye et al. 2015; Pambou Nziengui et al. 2016). Studying this tropical wood under cyclic loading is thus crucial to learning about the durability of timber structures designed using this species.

The background literature suggests that the mechanical behavior of Aucoumea Klaineana Pierre has not been sufficiently studied (Pambou Nziengui et al. 2015, Odounga et al. 2016). Some authors however have investigated its behavior in various fields of the wood sciences. For instance, Safou Tchiama et al. (2007) explained the physicochemical characteristics of $A K P$ in the goal of initiating a wood industrial waste recovery process in Gabon, by means of formulating wood based-composites. In the same manner, Medzegue et al. (2007) revealed the influence of humidity and soil type in the physical and mechanical properties of $A K P$. These examples show that over a specific period, the focus was aimed at a simple characterization of this species (Brancheriau et al. 2002). Recent investigations of $A K P$ mechanical behavior under different loadings (Brancheriau et al. 2010) and natural drying processes (Ikogou et al. 2016) have been pursued without considering the combined impact of environmental conditions and loading effects. Moreover, Odounga et al. (2016) examined the fracture toughness of $A K P$ at room temperature only under a tensile loading, with results being compared to other tropical species. Such a detailed evaluation can be justified by the fact that this species is the most widely harvested and used in Gabon (Safou Tchiama et al. 2007, Medzegue et al. 2007) as well as around the world. It appears essential to determine the impact of humidity variation on the $A K P$ mechanical behavior in order to predict the behavior of $A K P$ wood-based structures, yet the mechanical behavior of $A K P$ under cyclic compressive loading has not been sufficiently studied (Pambou Nziengui et al. 2015).

The objective of this work is to identify the correlation, or experimental impact, of both moisture content (MC) coupled with cyclic loading and loading intensity on the mechanical behavior of $A K P$ subjected to longitudinal compression. 


\section{Materials and methods}

\section{Materials}

The material used in this work is Aucoumea Klaineana Pierre (AKP), which is a tropical wood species that grows extensively in central Africa (Fig. 1a); it is considered an endemic species of the Gabon forest yet can also be found in Cameroon, Congo and Equatorial Guinea. AKP is harvested when its diameter at breast height exceeds $0.7 \mathrm{~m}$, as observed in Figure $1 \mathrm{~b}$ (Medzegue et al. 2007). AKP specimens from the Congo Basin rain forest (Gabon) were used for our experiments; these woods were delivered to the laboratory by our partners after first being sized to sawn timber (Fig. 1c). The choice of specimens studied herein was made randomly.

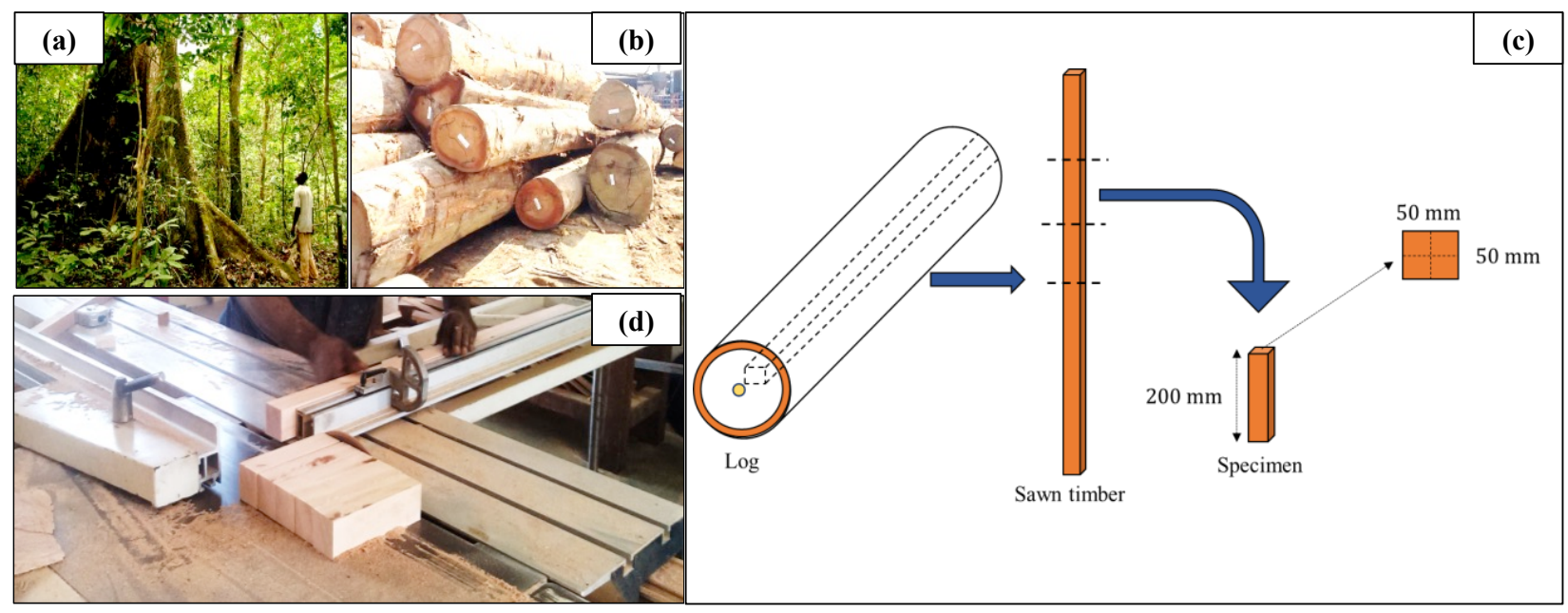

Figure 1: a) hillsides of $A K P$ in a Gabon forest; b) view of stored $A K P$ woods on the premises of Gabon's Société Equatoriale de Déroulage (S.E.D.); c) specimen preparation procedure; d) sizing of sawn timber into specimens

\section{Methods}

Six clear specimens of these $A K P$ timbers sawn along the fiber axis were dimensioned according to Standard ASTM-D-143 (ASTM-D-143, 2014) (Fig. 1d). Figure 1c also shows the technique employed to cut the various samples. The geometric shape and dimensions of the specimens can be visualized. Twenty-two specimens, dimensioned according to the American Standard ASTM-D-143 and conditioned at different MC levels, were tested; Table 1 lists the set of sample characteristics. The choice of samples tested herein was made so as to avoid those specimens with initial flaws like cracks and knots.

As observed in Table 1, 22 samples dimensioned at $50 \times 50 \times 200 \mathrm{~mm} 3$ for the compression tests, as shown in Figure 1c, were selected. As a next step, the samples were moistened with liquid water in order to obtain the corresponding $\mathrm{MC}$, according to Equation 1. 
Table 1. Characterization of the $A K P$ specimens studied

\begin{tabular}{|cccccccc|}
\hline Sample No & $\mathrm{l}(\mathrm{mm})$ & $\mathrm{t}(\mathrm{mm})$ & $\mathrm{L}(\mathrm{mm})$ & $\mathrm{MC}(\%)$ & $\mathrm{M}(\mathrm{g})$ & $\delta\left(\mathrm{g} / \mathrm{cm}^{3}\right)$ & Type of load \\
\hline 1 & 49.0 & 51.0 & 210.0 & 52.6 & 186.0 & 0.354 & Static load \\
2 & 51.0 & 50.0 & 210.0 & 31.4 & 179.0 & 0.334 & Static load \\
3 & 50.0 & 51.0 & 200.0 & 25.2 & 201.0 & 0.394 & Static load \\
4 & 49.0 & 51.0 & 205.0 & 30.7 & 197.0 & 0.384 & Cyclic load \\
5 & 50.5 & 51.0 & 210.0 & 20.5 & 240.0 & 0.443 & Static load \\
7 & 50.5 & 51.0 & 210.0 & 39.0 & 188.0 & 0.347 & Static load \\
9 & 50.5 & 51.5 & 205.0 & 26.2 & 211.0 & 0.395 & Cyclic load \\
10 & 50.5 & 51.0 & 210.0 & 20.1 & 211.0 & 0.390 & Cyclic load \\
11 & 50.0 & 50.5 & 205.0 & 40.9 & 179.0 & 0.345 & Cyclic load \\
12 & 50.5 & 50.5 & 200.0 & 27.7 & 184.0 & 0.360 & Static load \\
13 & 51.5 & 51.5 & 205.0 & 36.0 & 192.0 & 0.353 & Cyclic load \\
14 & 51.0 & 50.5 & 210.0 & 37.3 & 182.0 & 0.336 & Static load \\
15 & 51.0 & 50.0 & 205.0 & 52.2 & 194.0 & 0.371 & Static load \\
16 & 51.0 & 50.0 & 201.0 & 82.3 & 246.0 & 0.479 & Static load \\
18 & 51.0 & 51.5 & 205.0 & 27.0 & 183.0 & 0.339 & Static load \\
21 & 50.5 & 51.5 & 205.0 & 24.0 & 184.0 & 0.345 & Static load \\
22 & 50.0 & 50.0 & 210.0 & 40.5 & 203.0 & 0.386 & Static load \\
24 & 51.0 & 52.0 & 210.0 & 18.0 & 291.0 & 0.522 & Static load \\
25 & 50.0 & 51.0 & 205.0 & 23.5 & 202.0 & 0.386 & Static load \\
26 & 52.0 & 50.5 & 200.0 & 28.1 & 185.0 & 0.352 & Static load \\
27 & 51.0 & 50.5 & 200.0 & 17.2 & 244.0 & 0.473 & Cyclic load \\
28 & 50.0 & 50.0 & 201.0 & 24.0 & 207.0 & 0.412 & Cyclic load \\
\hline
\end{tabular}

$$
M C(\%)=\frac{M_{H}-M_{0}}{M_{0}}
$$

Two loading methods were introduced. The first entails the static compressive loading, with 15 samples being loaded (Fig. 2) onto a $100 \mathrm{kN}$-capacity electromechanical press until rupture. For this experimental campaign, the objective is to ascertain the mechanical characteristics of $A K P$ samples under a static compressive loading (Table 3). Results obtained for the static loading were statically analyzed using the R.3.4.0. software package. The second campaign pertains to the cyclic compressive loading and was performed on 7 samples. These specimens were each gradually loaded 5 times in the elastic zone. In considering the fact that each sample held a specific MC, the first loading level was set at $30 \%$ of the maximum breaking strength of the driest specimen tested under the static compressive loading. Then, a 5,000-N increment was added at each subsequent loading level (Table 2). Each cycle combined a loading path and an unloading path (Figures 3 and 4). The transition time between the end of the unloading path of the previous cycle and the beginning of the loading path of the subsequent cycle was 2 minutes.

Table 2. Level of each selected loading cycle

\begin{tabular}{cc}
\hline Cycle no. & Load level $(\mathrm{kN})$ \\
\hline 1 & 15.0 \\
2 & 20.0 \\
3 & 25.0 \\
4 & 30.0 \\
5 & 35.0 \\
\hline
\end{tabular}




\section{Results and discussion}

\section{Static compression}

Figure 2 shows the evolution in the relationships between stress and strain of the specimens tested under a static compressive loading. The curves of these results have been divided into two groups: Figure 2a samples with an MC of above 30\%, and Figure $2 \mathrm{~b}$ specimens with an $\mathrm{MC}$ of below $30 \%$.

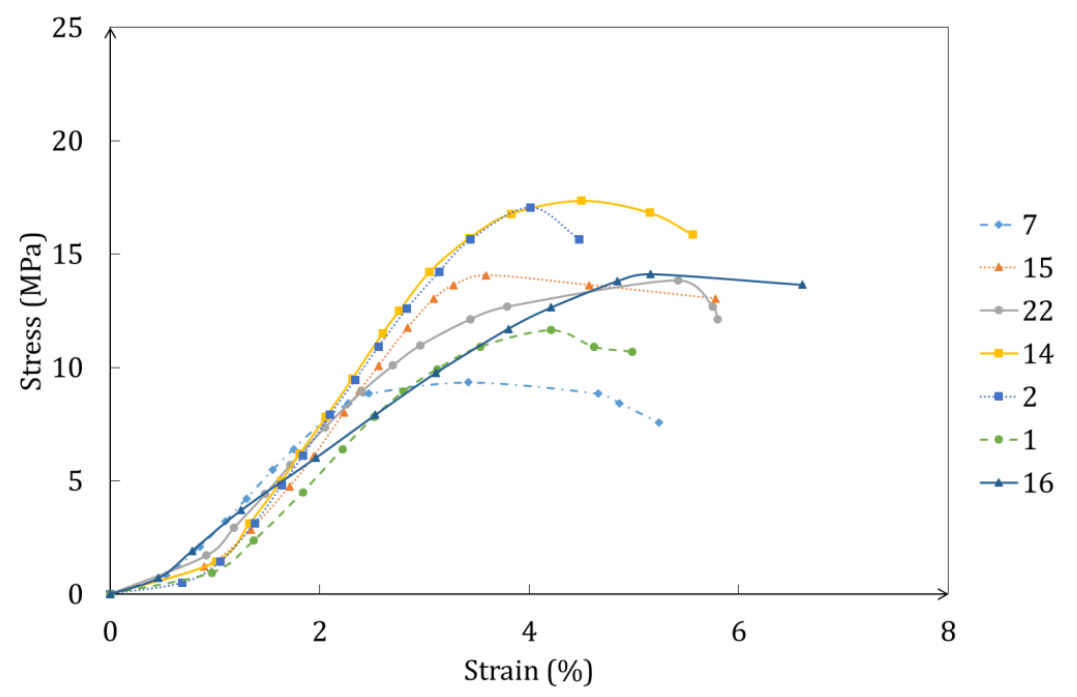

a)

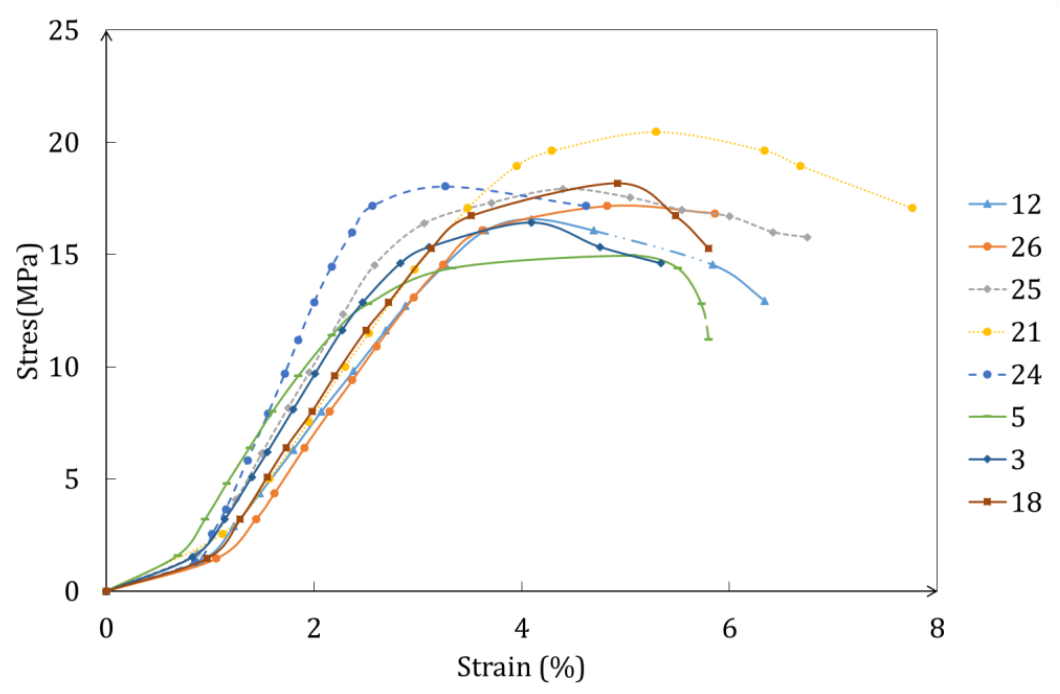

b)

Figure 2. Stress-strain relationships of samples with: a) $\mathrm{MC}>30 \%$, and b) $\mathrm{MC}<30 \%$

On each curve (Fig. 2) for the static loading, three different parts can be distinguished, namely: a linear part representing the reversible area where the modulus of elasticity (MOE) of AKP (see Table 3 ) is defined; a plastic area coinciding with the irreversible area; and a last part representing the specimen rupture area. According to these curves, the MOE and maximum stress (MS) of each $A K P$ specimen tested at a different MC level have been calculated and presented in Table 3 . The specimens from each of these two families of curves (i.e. with $\mathrm{MC}<30 \%$ and with $\mathrm{MC}>30 \%$ ) follow practically 
the same evolution. The choice of a $30 \%$ limit was made in accordance with the literature, as the fiber saturation point (FSP) value of $A K P$ equals 30\% (Medzegue 2007, Ndong Meye et al. 2015).

Table 3.Mechanical parameters of the specimens in static loading

\begin{tabular}{|c|c|c|c|}
\hline & Specimen no. & $\mathrm{MOE}(\mathrm{kPa})$ & $\mathrm{MS}(\mathrm{MPa})$ \\
\hline \multirow{8}{*}{$\begin{array}{c}\text { Specimens with } \\
\mathrm{MC}<30 \%\end{array}$} & 3 & 7.11 & 16.43 \\
\hline & 5 & 9.60 & 14.95 \\
\hline & 12 & 5.98 & 16.58 \\
\hline & 18 & 7.03 & 18.18 \\
\hline & 21 & 6.53 & 20.47 \\
\hline & 24 & 10.66 & 18.03 \\
\hline & 25 & 8.45 & 17.92 \\
\hline & 26 & 6.88 & 17.16 \\
\hline \multirow{7}{*}{$\begin{array}{c}\text { Specimens with } \\
\text { MC }>30 \%\end{array}$} & 1 & 4.70 & 11.64 \\
\hline & 2 & 6.48 & 17.06 \\
\hline & 7 & 5.00 & 9.34 \\
\hline & 14 & 6.66 & 17.35 \\
\hline & 15 & 6.34 & 14.06 \\
\hline & 16 & 4.00 & 14.11 \\
\hline & 22 & 5.81 & 13.84 \\
\hline
\end{tabular}

\section{Cyclic compressive loading}

Figure 3 shows a representation of the typical curve of one cycle (both loading and unloading paths) obtained during the cyclic tests. The parameter $\left(l_{i}=\mathrm{PD}\right)$ denotes the residual amplitude of plastic strain; it is used to characterize and understand the mechanical behavior of the specimen for the duration of the cyclic compressive loading. This $l_{i}$ parameter, as depicted in Figure 3 , is equivalent to plastic strain.

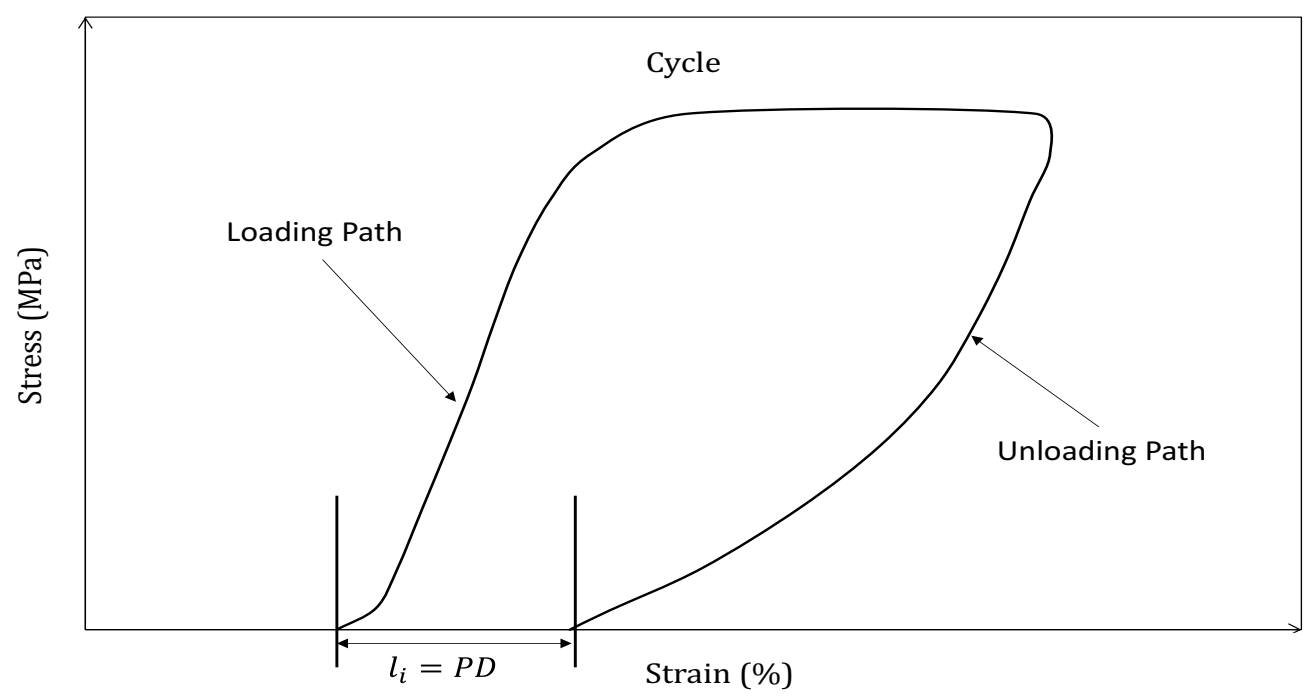

Figure 3. Diagram of a cycle and the various parameters studied in this work

Figure 4 displays the cyclic stress-strain relationships of $A K P$ specimens with an MC of below $30 \%$ tested during the cyclic compressive loading, which is composed of loading, unloading and reloading 
paths. This figure indicates nearly the same evolution in test specimen stress-strain curves. Each specimen curve may be divided into two parts in order to better understand the response of the specimen under the corresponding loading, i.e. an initial part with cycles exhibiting practically the same amplitude (permanent displacement, PD). This observation pertains to the first 3 loading cycles (Table 4). A second part, after the third cycle, contains an amplitude rise (Table 4), which could be explained by the fact that the linear limit (yield point) of the cyclic compressive test was exceeded. The first conclusion drawn is that a yield point exists during a cyclic longitudinal compressive test and after this point, the PD amplitude of each cycle increases with stress intensity.
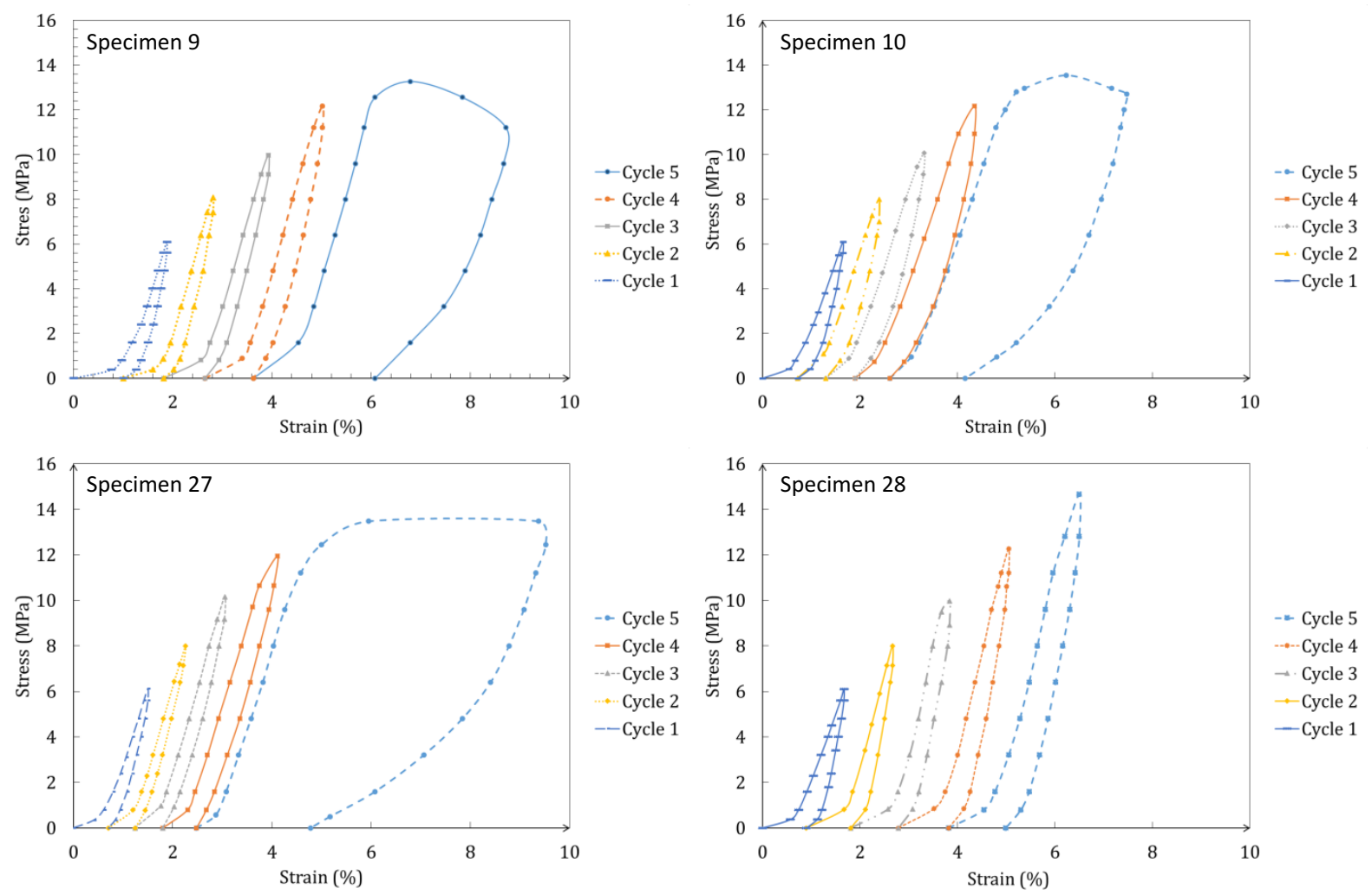

Figure 4 . Cyclic stress-strain evolution curves for specimens with an MC below 30\%

Figure 5 shows the cyclic stress-strain evolution curves for specimens with an MC above $30 \%$. Despite the fact that the MC of specimens in this group exceeds FSP, the result is practically the same in both groups (specimens with MC values of below 30\% and above 30\%). Based on the evolution of each curve, it can be concluded that the fact each specimen's MC value lies above or below the FSP value has no real impact on the $A K P$ behavior in a cyclic longitudinal compressive test. 

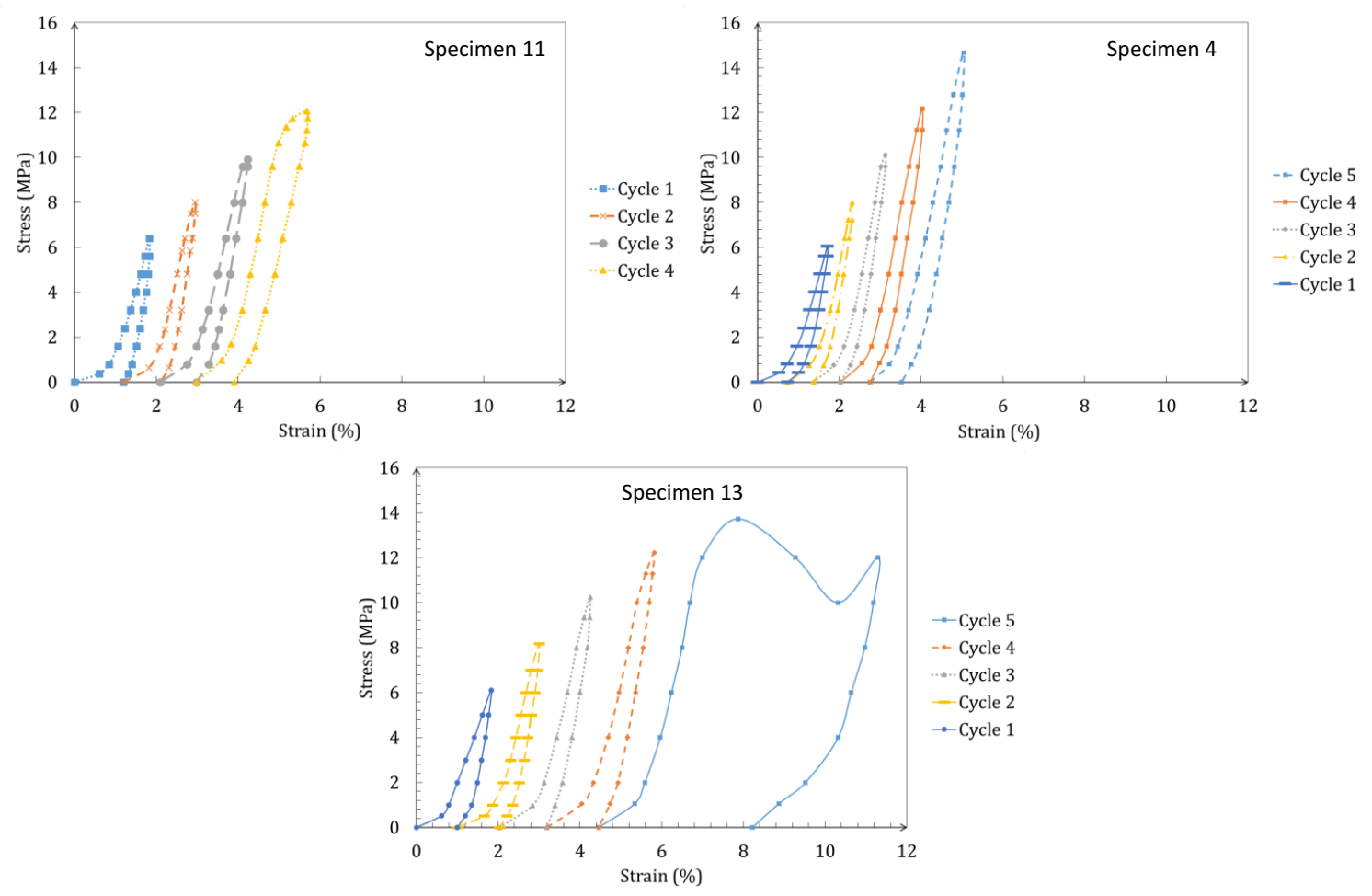

Figure 5. Cyclic stress-strain evolution curves for specimens with an $\mathrm{MC}$ above $30 \%$

\section{Comparison and statistical analysis between the PD amplitudes}

Table 4 shows the comparisons and results derived between the PD amplitudes of each cycle for each specimen. The previous tests conducted on the permanent displacement amplitudes of each cycle (Table 4) indicate that for $71 \%$ of all specimens studied, a significant difference exists between the amplitudes after a number of cycles. For all 7 AKP specimens loaded, the PD amplitude in $57 \%$ of the samples changes after the third cycle, and $14 \%$ after the fourth cycle. According to Ikogou et al. (2016), on the basis of these aforementioned tests, a cyclic compressive limit for $A K P$ is generated experimentally.

Table 4. Comparisons between the PD amplitudes of each loading cycle

\begin{tabular}{cccccc}
\hline & Specimen no. & $L_{1} / L_{2}$ & $L_{2} / L_{3}$ & $L_{3} / L_{4}$ & $L_{4} / L_{5}$ \\
\hline \multirow{3}{*}{ Specimens with } & 4 & 0.84 & 0.82 & 0.79 & 0.74 \\
MC $>30 \%$ & 11 & 0.76 & 0.86 & 0.38 & - \\
& 13 & 0.78 & 0.93 & 0.76 & 0.09 \\
\hline \multirow{3}{*}{ Specimens with } & 9 & 1.00 & 0.84 & 0.62 & 0.14 \\
MC $<30 \%$ & 10 & 0.79 & 0.87 & 0.66 & 0.22 \\
& 27 & 0.85 & 0.72 & 0.65 & 0.09 \\
& 28 & 0.84 & 0.96 & 0.80 & 0.70 \\
\hline & Mean & 0.84 & 0.86 & 0.66 & 0.33 \\
& SD & 0.05 & 0.05 & 0.10 & 0.26 \\
\hline
\end{tabular}


In Table $4, L_{i}$ represents the permanent displacement amplitude of each cycle $i$. According to Table 4 and the comparisons drawn between amplitudes $\left(L_{i} / L_{i+1}\right)$, no significant differences exist between amplitudes $L_{1}, L_{2}$ and $L_{3}(\mathrm{SD}=0.5)$, yet a difference does appear after the third cycle $\left(L_{3} / L_{4} ; \mathrm{SD}=\right.$ $0.10)$.

SD: Standard deviation

\section{Influence of MC and number of cycles on the AKP behavior}

Figure 6 shows the relationship between $\mathrm{MOE}$ and $\mathrm{MC}$ of $A K P$ for a static compressive loading. The MOE decreases as MC rises. For specimens with an $\mathrm{MC}<30 \%$, little dispersion is found between their MOE values, but beyond an MC $>30 \%$ their MOE values become more widely dispersed.

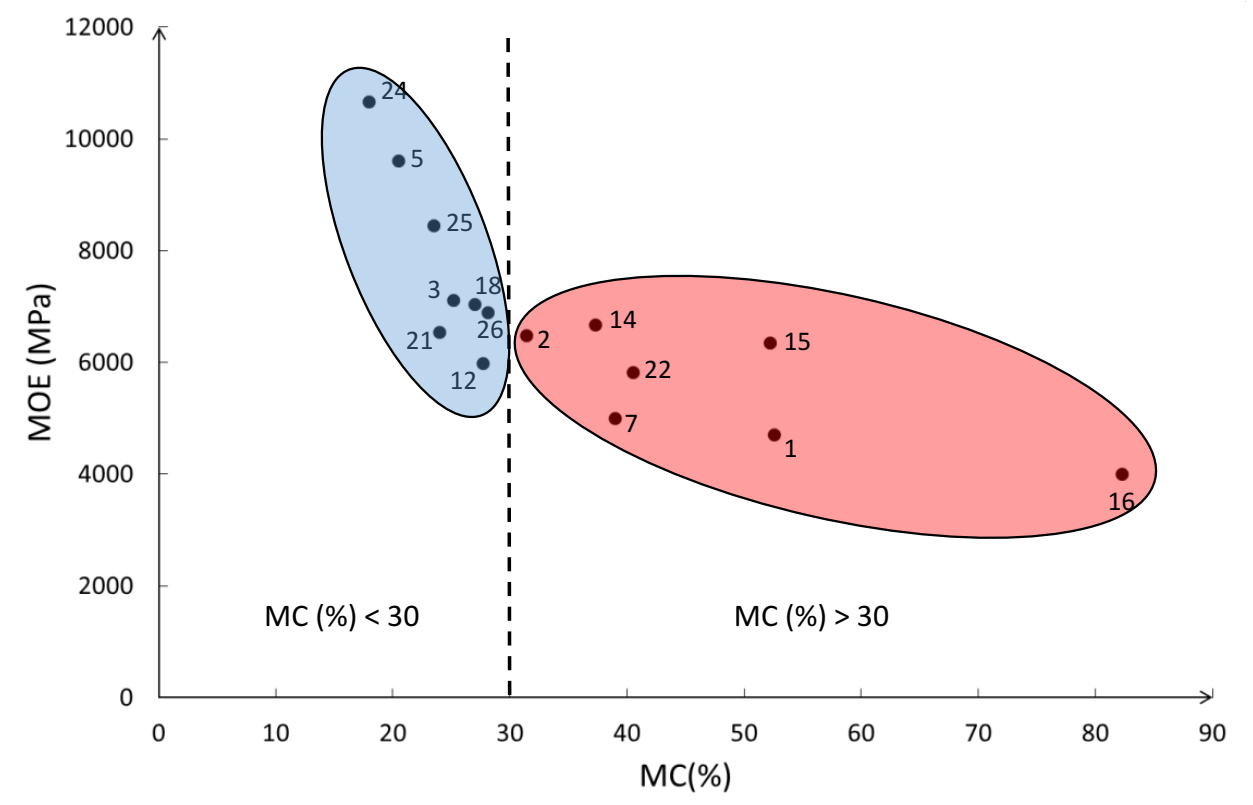

Figure 6. Evolution of MOE vs. MC of $A K P$ specimens tested under static loading

To justify these results, static analyses have been performed on these two groups (specimens with $\mathrm{MC}<30 \%$ and with $\mathrm{MC}>30 \%$ ). Figure 7 shows the linear regression plots of both groups. For the first one $(\mathrm{MC}<30 \%)$, the correlation test analysis clearly demonstrates a strong correlation $(\mathrm{p}<$ $0.001 ; r=-0.917)$ between the MOE and MC of the specimens. To the same extent, the simple static linear regression test also indicates a strong relationship $\left(\mathrm{R}^{2}=0.841\right)$ between MOE and MC for this group. For the second group ( $\mathrm{MC}>30 \%)$, the correlation test shows a low correlation $(\mathrm{p}<0.055 ; \mathrm{r}$ $=0.749$ ) between specimen $\mathrm{MOE}$ and $\mathrm{MC}$, yet with a relationship between MOE and MC not clearly established. The simple linear regression test for this group ( $\mathrm{MC}>30 \%)$ corroborates this limited impact $\left(R^{2}=0.474\right)$ of MC on MOE. This impact can be explained by the fact that an $\mathrm{MC}=30 \%$ lies above the FSP of $A K P$. This statement is justified by the dispersion of MOE values around the FSP of $A K P(26 \%<\mathrm{FSP}<30 \%)$. On the basis of this result, an impact is generated on the $\mathrm{MC}$ variation in the $A K P$ behavior, but this behavioral impact differs from FSP, either below or above. 

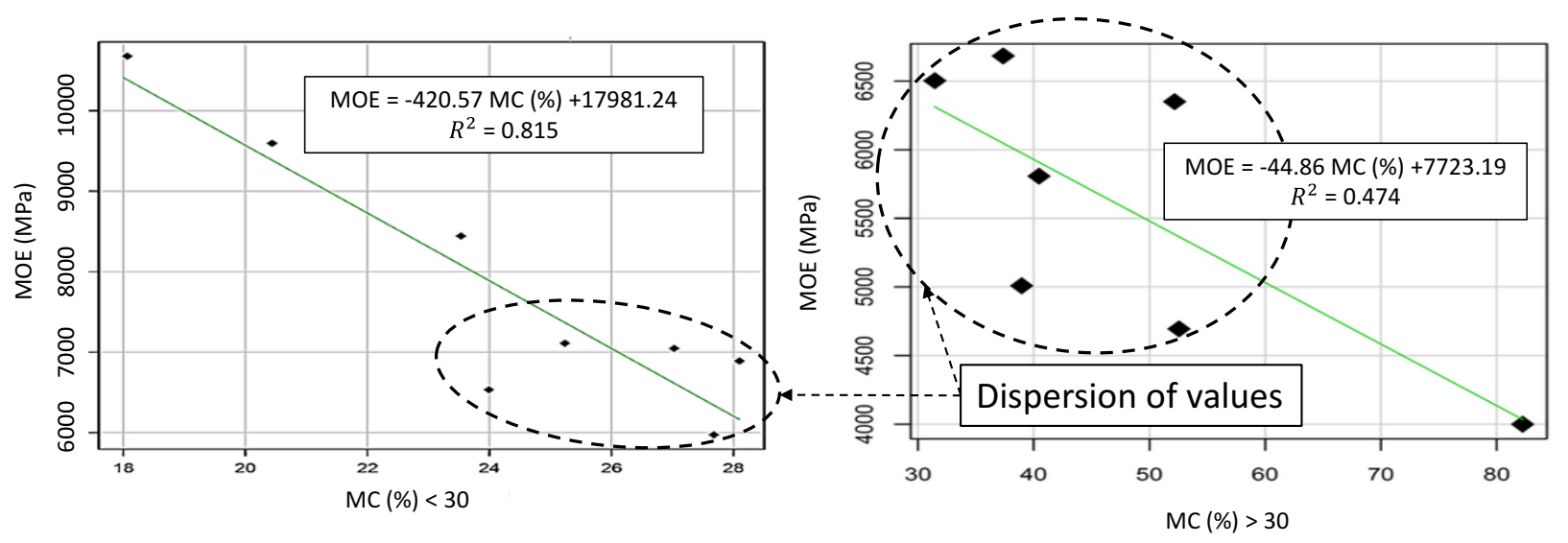

Figure 7. Linear regression plot between the MOE obtained on each specimen loaded in statics and its MC

Figures 8 and 9 also present the impact of $\mathrm{MC}$ on $A K P$ specimen behavior. During the first loading cycle (Fig. 8), we note a decrease in MOE as MC increases. This state is in agreement with the relationship obtained in Figure 6 for static loading, but after the first cycle, MOE increases (Fig. 8) despite the fact that MC is increasing. This state has been explained by Sandberg et al. (2013), and also observed by others authors (Kutnar et al. 2015), who showed that compressing wood in the transverse direction reduces the void volume of lumens in the wood material and increases wood density. Density however is correlated with MOE (Dwianto et al. 1998, Wei Xu 2007); a wood density increase is of benefit to the wood MOE. This conclusion can be also observed for the $A K P$ specimens tested herein. The fact that $\mathrm{MC}$ is increasing exerts no real influence on the cyclic compression behavior of $A K P$, according to Figure 8, yet this offers a critical view of the variation in MOE vs. number of cycles (Fig. 10). Let's remark that the $A K P$ aging rate in cyclic compression depends on the MC history of the specimen.

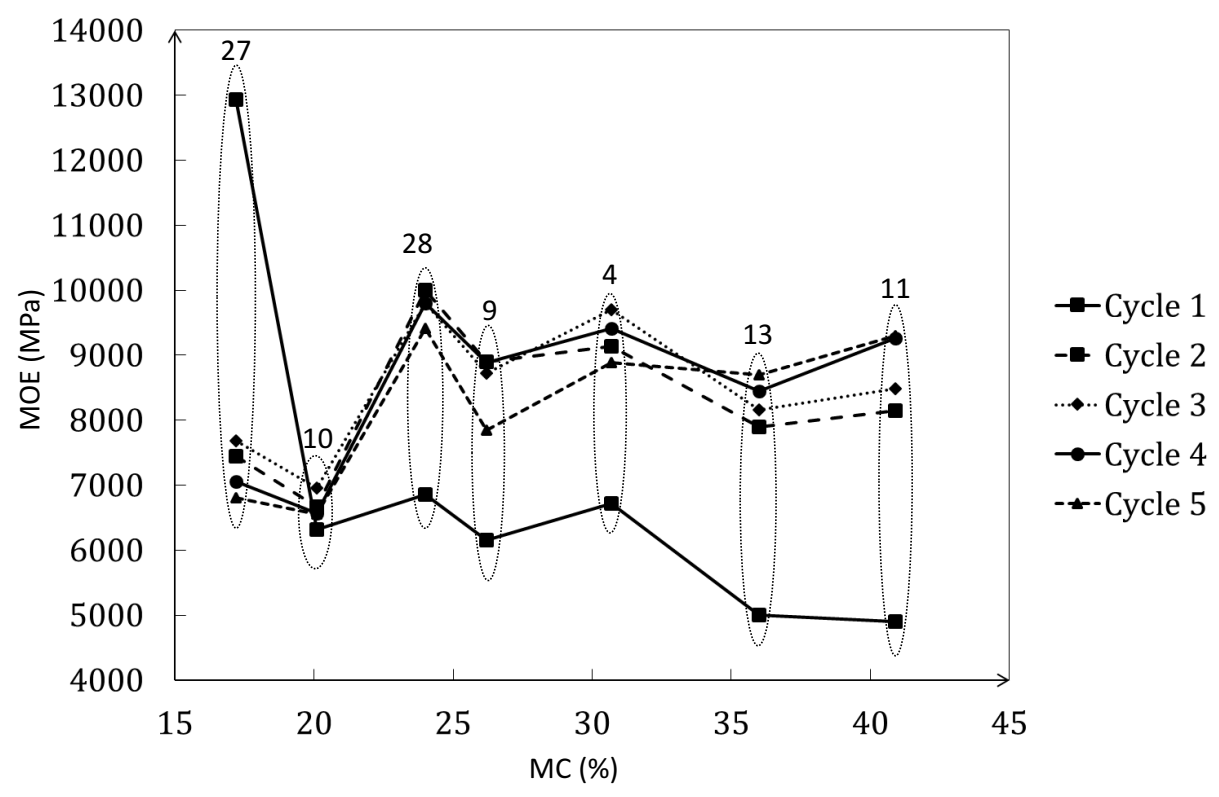

Figure 8. Evolution of MOE vs. MC at different cycles for each $A K P$ specimen under study 


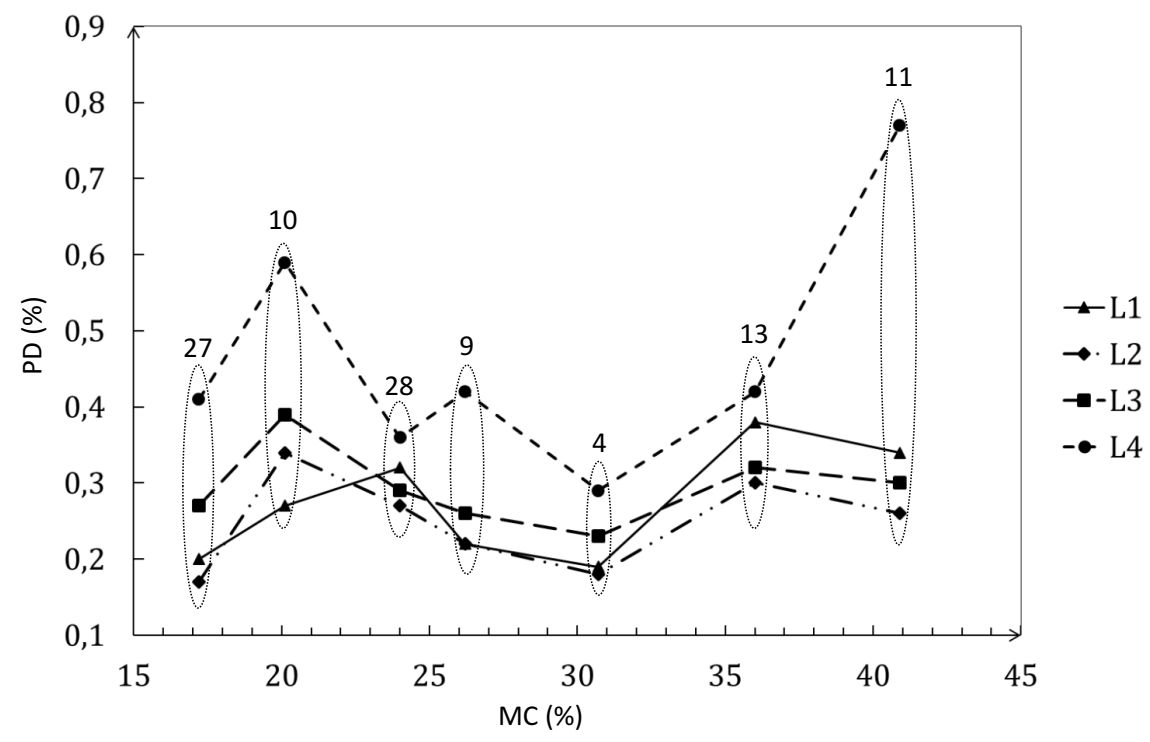

Figure 9. PD evolution with MC variations and number of cycles

The stiffness of $A K P$ decreases with a rise in MC (Fig. 10) under cyclic compressive loading. This rate of decrease is fast for the specimen, which has an $\mathrm{MC}<30 \%$, and slow for the specimens with an $\mathrm{MC}>30 \%$. This phenomenon is called plasticization and can be explained by the fact that when wood absorbs water, it becomes more flexible. Figures 9 and 10 show the impact of the evolution in number of cycles (or the impact of intensity). According to these figures, the PD amplitude increases with stress intensity (Fig. 9). The first three cycles overlap; this state confirms the hypothesis given in Figures 8 and 9 and Table 4, i.e. an elasticity limit exists for a cyclic loading. According to Figure 9, let's also observe a linear correspondence between the stress history and the strain history for a progressive cyclic response. In this case, a progressive cyclic load is applied on the specimens in order to produce a material response up until failure.

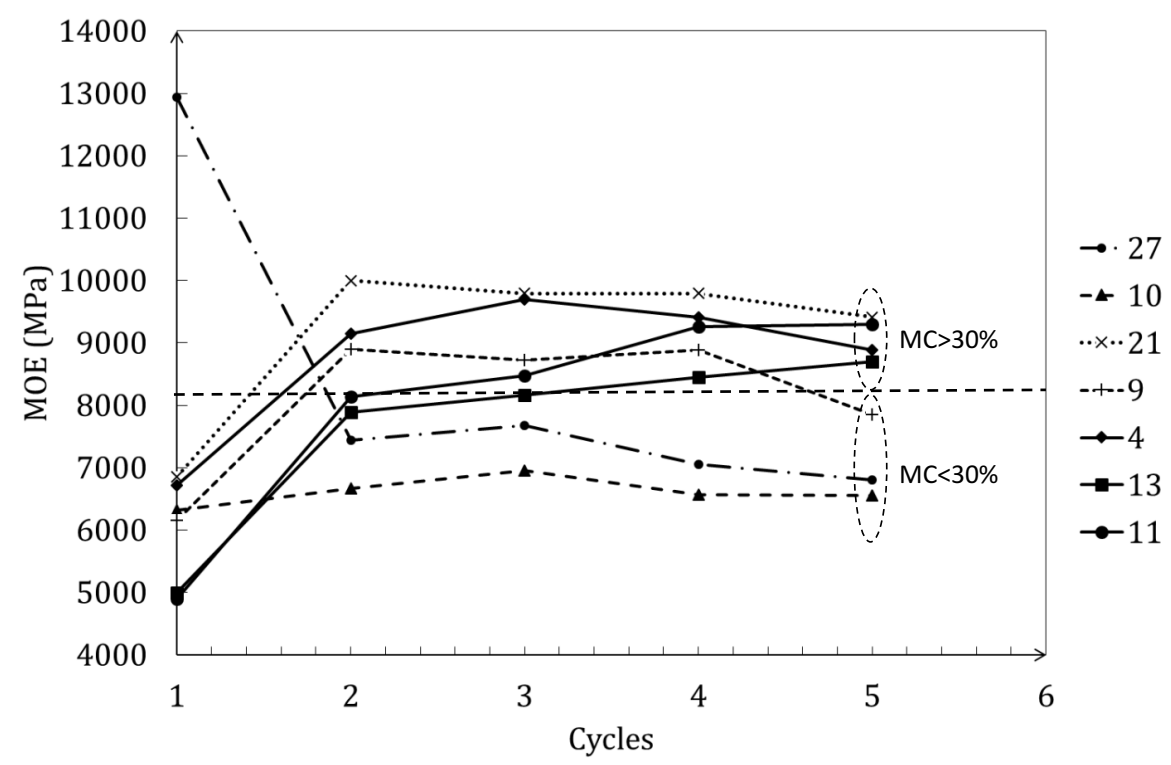

Figure 10. Evolution of MOE vs. number of cycles in each specimen 
On the basis of these results, we can state the hypothesis that for a progressive cyclic compressive loading before failure, two areas are found: an elastic one of the cyclic compressive loading of $A K P$, and a plastic one of the cyclic compressive loading. The elastic area of $A K P$ in cyclic compressive loading is considered herein as the part where the mechanical properties of $A K P$ have not considerably changed, but the plastic area is the part where its mechanical properties have changed to a noticeable extent. As noted regarding this research work, a boundary is present between these two parts, and this boundary can be considered as the yield point of $A K P$ in cyclic compressive loading.

\section{Conclusion}

The purpose of this work has been to study the impact of moisture content (MC), coupled with static and cyclic compressive loadings on the mechanical behavior of Aucoumea Klaineana Pierre (AKP). Results show that as with major wood species, As MC increases, it decreases the $A K P$ strength. This result is valid for both types of compressive loading (i.e. static and cyclic) and for each specimen. In addition, the number of loading cycles exerts an impact on the mechanical behavior of $A K P$; this impact is perceptible beyond a cyclic limit that could be defined as a cycle yield point of $A K P$ under a cyclic compressive loading. These main results also reveal that coupling the number of loading cycles with the variation in $A K P$ moisture content amplifies the loss of $A K P$ mechanical performance under loading. This work was specifically focused on an experimental study of the effects of MC variation combined with progressive cyclic compressive loading. In the upcoming work, it will be necessary to develop a predictive experimental mechano-sorptive behavioral model of $A K P$ loadunload-reload under a cyclic compressive loading. Moreover, the analytical and numerical cyclic models that take viscoelastic aspects into account will be proposed in order to simulate the behavior of tropical species under complex loading processes.

\section{Acknowledgments}

The authors would like to acknowledge the valuable contributions of the Central African Network of Forest and Environmental Training Institutes (RIFFEAC), the Gabon National Scholarships Agency (ANBG) and the National Research Agency (ANR) for their financial support of this work through the CLIMBOIS ANR-13-JS09-0003-01 project, as well as the labeling awarded by France's ViaMéca cluster.

\section{References}

ASTM-D-143. (2014) Annual book of American Society for Testing Materials. ASTM D143-14, Standard Test Methods for Small Clear Specimens of Timber. ASTM International, DOI: 10.1520/D0143

Brancheriau, L., Bailleres, H., \& Guitard, D. (2002) Comparison between modulus of elasticity values calculated using 3 and 4 point bending tests on wooden samples. Wood Science and Technology, $36(5), 367-383$.

Brancheriau, L., Kouchade, C., \& Brémaud, I. (2010) Internal friction measurement of tropical species by various acoustic methods. Journal of wood science, 56(5), 371-379.

Dwianto, W., Norirnoto, M., T., Tanaka, F., Inoue, M., \& Liu, Y. (1998) Radial compression of sugi wood ( Cryptomeria japonica D . Don ). Holz als Roh-und Werkstoff, 56 (6), 403-411.

Gerhards, C. C., (2007) Effect of moisture content and temperature on the mechanical properties of wood: an analysis of immediate effects. Wood and Fiber Sciences, 14(1), 4-36.

Ikogou, S., Pambou Nziengui, C. F., Moutou Pitti, R., Ekomy Ango, S. (2016) Experimental characterization of Gaboon species under cyclic compressive loading. World Conference of Timber Engineering (WCTE), Vienna, Austria. 
Kutnar, A., Sandberg, D. \& Haller, P. (2015) Compressed and moulded wood from processing to products. Holzforshung , 69(7), 885-897.

Manfoumbi Boussougou, N., Sauvat N. Dubois F., Pop, O. (2010) Experimental decoupling of hydrics and postponed phenomena of timber structures in controlled climate conditions. Word Conference on Timber Engineering (WCTE), 20-24 June 2010, Trentino, Italy. ISBN:9781622761753

Manfoumbi Boussougou, N., Dubois F., Sauvat N. (2012) Behavior in service of beams in flexion: adaptation of the eurocode 5 to a tropical climate. Word Conference on Timber Engineering (WCTE), Auckland, 16-19, July.

Manfoumbi Boussougou, N.,Nguyen , T. A.,Angellier, N., Dubois, F., Ulmet, L., Sauvat, N. (2014) Experimental and numerical aspects in diffusion process characterization in tropical species. European Journal of Environmental and Civil Engineering,18(9), 963-982

Medzegue, M. J., Grelier, S., M'Batchi, B., Nziengui, M., \& Stockes, A. (2007) Radial growth and characterization of juvenile and adult wood in plantation grown okoumé (Aucoumea klaineana Pierre) from Gabon. Annals of Forest Science, 64(8), 815-824. Available at: http://link.springer.com/10.1051/forest:2007065.

Ndong Meye, S. L., Moutou Pitti, R., Ekomy Ango, S., Ikogou, S. (2015) Mechanical behavior of Aucoumea Klaineana Pierre subjected to desiccation. 4th day of the GDR 3544 "Sciences du Bois" - Clermont-Ferrand, 4-6 November 2015, DOI: 10.13140 / RG.2.1.4578.1200.

Odounga, B., Moutou Pitti, R., Toussaint, E., Grediac, M. (2016) Experimental Fracture Analysis of Tropical Species Using the Grid Method. Springer, DOI 10.1007/978-3-319-42195-7_2 .

Pambou Nziengui, C. F., Ikogou, S., Moutou Pitti, R., Ekomy Ango, S. (2015) Mechanical behavior of Aucoumea Klaineana Pierre under cyclic loading in compression. 4th day of the GDR 3544 "Sciences du Bois" - Clermont-Ferrand, 4-6 November 2015, DOI: 10.13140 / RG.2.1.2480.9680.

Pambou Nziengui, C. F., Moutou Pitti, R., Ikogou, S., Ekomy Ango, S. (2016) Mechanical behavior of Aucoumea Klaineana Pierre under cyclic loading in compression: effect of moisture. 5th day of the GDR 3544 "Sciences du bois" - Bordeaux, 8-10 November 2016.

Safou-Tchiama, R., Obame, S. N., Brosse, N., Soulounganga, P., \& Barhé, T. A. (2016) Investigating the potential of Aucoumea klaineana Pierre sapwood and heartwood wastes to produce cellulosic ethanol. African Journal of Biotechnology, 15(46), 2587-2595.

Safou-Tchiama, R., de Jéso, B., Akagah, A. G., Sèbe, G., \& Pétraud, M. (2007) A preliminary survey of the interfacial bonding of some tropical hardwoods towards succinic anhydride and 2-octen1-yl succinic anhydride molecules: Impact of lignin and carbohydrate polymers structure on the chemical reactivity. Industrial Crops and Products, 26(2), 173-184.

Sandberg, D., Haller, P. \& Navi, P. (2013) Thermo-hydro and thermo-hydro-mechanical wood processing : An opportunity for future environmentally friendly wood products. Wood Material Science and Engineering. 8(1), 64-88.

$\mathrm{Xu}, \mathrm{W}$. (2007) Influence of vertical density distribution on bending modulus of elasticity of wood composite panels: a theoretical consideration. Wood and fiber science, 31(3), 277-282. 